\title{
ПРЕДПРИНИМАТЕЛЬСКИЕ ИННОВАЦИИ ВО ВЬЕТНАМЕ: ПРОБЛЕМЫ И ИХ РЕШЕНИЯ
}

\author{
(c) 2021 Вы Дык Ань \\ аспирант департамента менеджмента \\ Финансовый университет при Правительстве Российской Федерации, Россия, Москва \\ E-mail:voshka93@yandex.ru
}

Предпринимательские инновации стали одной из самых актуальных тем во многих странах в последние годы. Во Вьетнаме предпринимательские инновации были определены как основной фактор, обеспечивающий успех предприятий. Тем не менее, показатели предпринимательских инноваций во Вьетнаме все еще отстают от показателей многих стран региона, таких как Сингапур и Малайзия. Кроме того, политический механизм Вьетнама на самом деле не создал сильного продвижения для запуска деятельности. Эта статья посвящена не только анализу текущего состояния продвижения предпринимательских инноваций во Вьетнаме, но и выявлению проблем, связанных с предпринимательскими инновациями во Вьетнаме. Эта статья также предлагает решения для продвижения предпринимательских инноваций во Вьетнаме.

Ключевые слова: Стартап, инновации, предпринимательство, экономика.

Введение. Согласно международной научной литературе, стартап - это бизнес или временная организация, предназначенная для нахождения схемы действий, которые можно быстро повторить или расширить (Blank, 2010). Во Вьетнаме термин «стартапы» (Startup) часто используется, чтобы отличить его от обычных предприятий, таких как открытие ресторана или магазина одежды.

Однако не у каждого есть потенциал для открытия частного бизнеса (Learned, 2002). Потенциальный предприниматель - это тот, кто пользуется возможностью, чтобы создать свою собственную компанию, как только появляется такая возможность (Shapero, 1981). Предпринимательство - это процесс, который начинается с признания возможностей, тем самым развивая идеи для реализации возможностей путем создания новой компании. Согласно данным Global Entrepreneurship Monitor, новый бизнес будет проходить 3 этапа: от формирования, разработки идей до создания бизнеса и, наконец, поддержания и развития бизнеса. В настоящее время исследователи во многих странах мира анализируют потенциалы стартапов. Прежде всего изучается положительный опыт тех стран, где создаются новые предприятия для обеспечения новых ценностей для всего общества.

Методология исследования. Эмпирические данные были собраны с помощью различных источников. Это позволило соединить обоснованные теоретические результаты с практическими обобщениями. Собранные данные были проанализированы и сопоставлены с предыдущими исследованиями, а также послужили основой для ответа на вопросы исследования.

Результаты исследования. Отчет от Глобального мониторинга предпринимательства за 2017-2018 годы (Global Entrepreneurship Monitor 2017/18 Report) является 19-м отчетом, который создан для отслеживания состояния стартапов по всему миру поэтапно от потенциальных предпринимателей до стартапов и стабильного роста в условиях экосистемы стартапов в каждой стране. Этот отчет основан на результатах опроса более 164 тысяч взрослых (Adult Population Survey (APS)) и опроса более 2000 экспертов (National Expert Survey - NES) в 54 странах (таблица 1).

Глобальный мониторинг предпринимательства оценивает качество экосистемы предпринимательских инноваций посредством экспертных опросов. Этот обзор фокусируется более всего на факторах, которые влияют на индивидуальных предпринимателей и их начальную деятельность, чем на макроэкономические факторы окружающей среды. В целом в экосистеме стартапов инфраструктура продолжает оставаться самым верхним показателем. Наименьший показатель у предпринимательского образования на школьном этапе. Положительным сигналом является то, что около половины показателей экосистемы стартапов в странах 
Таблица 1. Страны, принявшие участие в GEM 2017, по регионам

\begin{tabular}{|c|c|c|c|}
\hline Регион & $\begin{array}{c}\text { Страны, основанные на } \\
\text { своих факторах }\end{array}$ & $\begin{array}{c}\text { Страны, основанные на } \\
\text { эффективности }\end{array}$ & $\begin{array}{c}\text { Страны, основанные на } \\
\text { инновациях }\end{array}$ \\
\hline Африка & Мадагаскар & $\begin{array}{c}\text { Египет, Марокко, Южная } \\
\text { Африка }\end{array}$ & \\
\hline Азия и Океания & $\begin{array}{c}\text { Индия, Иран, Казахстан, } \\
\text { Вьетнам }\end{array}$ & $\begin{array}{c}\text { Китай, Индонезия, Ливан, } \\
\text { Малайзия, Саудовская } \\
\text { Аравия, Тайлайнд }\end{array}$ & $\begin{array}{c}\text { Австралия, Израиль, } \\
\text { Катар, Республика Корея, } \\
\text { Тайвань, Япония, ОАЭ }\end{array}$ \\
\hline $\begin{array}{c}\text { Латинская Америка и } \\
\text { Карибские острова }\end{array}$ & & $\begin{array}{c}\text { Аргентина, Бразилия, } \\
\text { Чили, Колумбия, } \\
\text { Эквадор, Гватемала, } \\
\text { Мексика, Панама, Перу, } \\
\text { Уругвай }\end{array}$ & Пуэрто-Рико \\
\hline Европа & & $\begin{array}{c}\text { Болгария, Босния и Герце- } \\
\text { говина, } \\
\text { Хорватия, Латвия, Поль- } \\
\text { ша, Словакия }\end{array}$ & $\begin{array}{c}\text { Кипр, Эстония, Франция, } \\
\text { Германия, Греция, Ирлан- } \\
\text { дия, Италия, Люксембург, } \\
\text { Нидерланды, Словения, } \\
\text { Испания, Швеция, Швей- } \\
\text { цария, Великобритания }\end{array}$ \\
\hline Северная Америка & & & Канада, США \\
\hline
\end{tabular}

улучшились по сравнению с 2016 годом, из которых наиболее сильным улучшением являются финансы для стартапов и предпринимательское образование на школьном этапе, а также динамика внутреннего рынка.

При сравнении экосистемы стартапов Вьетнама с 54 другими странами мира (GEM, 2017), выявлено, что у Вьетнама 2 самых высоких показателя это динамика внутреннего рынка (5 место из 54) и культура и социальные нормы (6 из 54). Инфраструктура - индекс с самым высоким средним показателем во Вьетнаме, заняла третье место среди 12 стартовых показателей экосистемы, тем самым заняв 10 место из 54 . Следующие два самых высоких показателя Открытость внутреннего рынка (12/54) и Правительственная Политика (13/54). Несмотря на то, что показатель правительственной политики составляет 2,4 балла из 5, он по-прежнему занимает 13 место из 54, показывая, что достижение хорошей и эффективной системы политики для поощрения предпринимательства и экономического развития является не только проблемой одного Вьетнама, но и большинства стран в мире. Три самых низких показателя в экосистеме стартапа во Вьетнаме (2017) - это Предпринимательские финансы (39/54), Предпринимательское образование на послешкольном этапе (40/54) и Государственные программы развития предпринимательства (43/54). (Таблица 2).

В целом условия ведения бизнеса имеет тенденцию к улучшению, они повышаются вместе с уровнем экономического развития, то есть если экономика растет, то условия ведения бизнеса, как правило, улучшаются.

Трудности и вызовы. Подача заявки на интеллектуальную собственность (ИС) или авторское право занимает много времени, а поданные заявки за границу редко принимается. Вопрос защиты прав ИС очень важен для стартапов. Однако в настоящее время во Вьетнаме процедуры регистрации ИС также требуют много времени, и мало эффективны, и плохо защищаются. Поэтому многим предприятиям приходится прилагать усилия для создания технологических барьеров для конкуренции.

Ограниченный капитал, а также механизмы и политика, связанные с мобилизацией капитала, являются одной из важных причин. Стартаппроекты часто начинаются с ограниченным собственным капиталом учредителей, в то время как возможность занимать деньги в банках или привлекать инвестиционные фонды очень низка. Хотя существует довольно много разных финансовых каналов, в действительности для стартапов по-прежнему часто бывает трудно испытывать недостаток в капитале. Фактически, нынешнее сообщество стартапов хочет, чтобы в истории привлечения капитала были более конкретные законы и институты, помогающие стартапам получить доступ и легко получить капитал от инвесторов. В частности, в Постановлении Правительства № 38/2018/ND-CР от 11 марта 2018 г. об инвестициях в инновационные стартапы не совсем ясны правила привлечения капитала. Между тем, фактор, который больше 
Таблица 2. Рейтинг показателей экосистемы стартапов во Вьетнаме за 2013-2017 годы.

\begin{tabular}{|l|c|c|c|c|c|c|c|c|}
\hline \multirow{2}{*}{$\begin{array}{c}\text { прловия для } \\
\text { предпнимательства }\end{array}$} & \multicolumn{2}{c|}{2017} & \multicolumn{2}{c|}{2016} & \multicolumn{2}{c|}{2015} & \multicolumn{2}{c|}{2014} \\
\cline { 2 - 11 } & Баллов & Рейтинг & Баллов & Рейтинг & Баллов & Рейтинг & Баллов & Рейтинг \\
\hline Динамика внутреннего рынка & 4,15 & 5 & 3,59 & 11 & 3,71 & 6 & 3,5 & 15 \\
\hline Культура и социальные нормы & 3,62 & 6 & 3,23 & 14 & 3,13 & 17 & 3,1 & 20 \\
\hline Инфраструктура & 4,19 & 10 & 4,07 & 17 & 3,75 & 39 & 3,58 & 43 \\
\hline Открытость внутреннего рынка & 2,79 & 12 & 2,51 & 28 & 2,43 & 52 & 2,66 & 32 \\
\hline Правительственная политика & 2,4 & 13 & 2,78 & 15 & 2,93 & 20 & 2,89 & 20 \\
\hline Постановления Правительства & 3,02 & 25 & 2,62 & 25 & 2,46 & 32 & 2,77 & 13 \\
\hline Передача технологии & 2,19 & 34 & 2,33 & 30 & 2,3 & 40 & 2,54 & 20 \\
\hline $\begin{array}{l}\text { Предпринимательское образова- } \\
\text { ние на школьном этапе }\end{array}$ & 1,83 & 34 & 1,57 & 47 & 1,83 & 51 & 1,97 & 46 \\
\hline $\begin{array}{l}\text { Услуги по поддержке предприни- } \\
\text { мательства }\end{array}$ & 2,82 & 36 & 2,93 & 42 & 2,93 & 41 & 2,89 & 45 \\
\hline Предпринимательские финансы & 2,27 & 39 & 2,12 & 50 & 2,37 & 44 & 2,4 & 42 \\
\hline $\begin{array}{l}\text { Предпринимательское образова- } \\
\text { ние на послешкольном этапе }\end{array}$ & 2,61 & 40 & 2,53 & 47 & 2,64 & 58 & 2,64 & 50 \\
\hline $\begin{array}{l}\text { Государственные программы } \\
\text { развития предпринимательства }\end{array}$ & 2,09 & 43 & 2,14 & 50 & 2,35 & 54 & 2,5 & 38 \\
\hline
\end{tabular}

всего беспокоит бизнес и который трудно обеспечить, - это создание фонда, хотя в Постановление упоминается.

В настоящее время правила, механизмы и политики для поддержки стартапов совершенствовались и совершенствуются все больше и больше, но многие материалы, требующие конкретных указаний, еще недоступны, что фактически затрудняет реализацию правил и политик. В нынешней институциональной системе инноваций и предпринимательства отсутствует правовая база с правильным регулированием для этих новых видов бизнеса. Это серьезный барьер, который мешает вьетнамским стартапам получить доступ к капиталу и вести свою деятельность. Предприятиям действительно нужны институты и правовые коридоры, чтобы стартапы могли найти лучший путь.

Хотя начальная ситуация во Вьетнаме улучшилась уже в 2017 году, доля людей, начинающих предпринимательскую деятельность, увеличилась, но все еще есть много признаков того, что Вьетнам уступает другим странам того же уровня, ну и также странам в своем регионе. $\mathrm{K}$ этим признакам можно отнести боязнь неудачи в бизнесе, свои предпринимательские способности, предпринимательский сектор и инновации в бизнесе. Таким образом, по сравнению с 2013-2015 годами слабые стороны экосистемы стартапов во Вьетнаме, такие как государственные программы развития предпринимательства, передача технологий, Правительственная поли- тика и т.д., не улучшились. Общим менталитетом стартапов является то, что государственные учреждения работают медленно, используя «запутанные» (непрозрачные) и неэффективные процедуры.

\section{Некоторые рекомендации и решения.}

Во-первых, продолжать совершенствовать, исследовать, выпускать новые и дополнять необходимые механизмы и политики для поддержки и продвижения среды стартапов, а также создавать благоприятные условия для привлечения финансовых ресурсов, чтобы стартапы имели свою точку. Применение конкретных финансовых механизмов и особой налоговой политики для организаций и частных лиц, начинающих деятельность или инвестирующих в стартапы.

Развитие финансового рынка с целью диверсификации каналов мобилизации капитала для стартапов, развитие фондовой биржи для стартапов, помощь предприятиям в мобилизации капитала напрямую от общества, решение трудностей в получении капитала, способствовать развитию рынка корпоративных облигаций; сосредоточить внимание на привлечении «ангельских» инвесторов и венчурных фондов для поддержки стартапов на ранней стадии развития во Вьетнаме.

Во-вторых, предприятиям необходимо лучше использовать финансовые знания и мобилизовать капитал, чтобы иметь возможность получить доступ к инвестиционному капиталу и привлечь его. Поощрение корпоративного фи- 
нансирования как со стороны предложения, так и со стороны спроса обеспечит больший успех вьетнамскому бизнесу. Предприятиям необходимо подготовить необходимые элементы при открытии бизнеса; Проактивно исследовать и обновлять информацию о политиках и законах, чтобы быстро улавливать, получать и использовать возможности и стимулы от политик и минимизировать риски в процессе запуска.

При реализации бизнес-идей стартапы часто сосредотачиваются на рынке и продажах. Но для того, чтобы предпринять твердые шаги и быть готовым к привлечению инвестиционного капитала, необходимо юридическое понимание. Соответственно, стартапы должны осознавать и ценить роль юриста в процессе бизнеспланирования. Чтобы было хорошо сделано составление и подписание соглашения о сотрудничестве, письменного обязательства или иного соглашения между членами-учредителями, направленного на ориентацию и создание плана конкретного партнерства, а также обеспечение прав и выгод и вклада членов в соответствии с принципом справедливости и выгоды всех сторон. В то же время следует проконсультироваться с профессиональным юристом по вопросам регистрации и защиты прав интеллектуальной собственности своих идей в соответствии с законодательством. Тщательно изучить правовые вопросы, связанные с выбором типа предприятия, подходящего для бизнес-целей и планов развития предприятия на каждом этапе создания и после его создания.

В-третьих, усиление роли бизнес-ассоциаций и отраслевых ассоциаций, продвижение роли моста между управляющими агентствами и бизнесом. Хорошее выполнение своей роли является важным каналом для критики политики в отношении бизнеса, позволяя бизнес-сообществу контролировать и оценивать деятельность государственных органов как основу для повышения качества обслуживания.

В-четвертых, укрепление связи и координации между государственными органами, корпоративными представительскими организациями и ассоциациями адвокатов, ассоциациями адвокатов для оказания правовой поддержки в конкретных ситуациях. Продвигать юридическую поддержку бизнеса во многих формах, таких как письмо, онлайн, телефон ...

Также можно разработать программы для поддержки и поощрения инновационных стар- тапов:

- Политика и программы поддержки должны быть направлены на начальные стадии бизнеса и создание бизнеса, но также должны стимулировать предпринимательскую деятельность на предприятии: пропагандировать, поддерживать и дать предприятиям руководство создания фонда развития науки и техники; реализовать льготную политику для предприятий, которые заняты предпринимательской деятельностью.

- Программы поддержки запуска должны быть не массовыми, а точечными и отдавать приоритет стартапам в ведущих отраслях. Согласно исследованию GEM, развитая экономика при переходе на более высокую ступень, должна подвергнуться экономической реструктуризации в сторону увеличения доли деловой активности в сфере переработки и обслуживания предприятий, особенно отрасли информационных и коммуникационных технологий, финансовых услуг, услуг по развитию бизнеса.

- Эффективно осуществлять политику поддержки, поощрения исследований и применения научно-технических достижений в производстве, продвигать услуги по поддержке развития рынка для повышения конкурентоспособности не только каждого предприятия, но и всей экономики страны в целом. Усилить информационную работу, информационно-пропагандистскую деятельность и наращивать потенциал в области интеграции с международной экономикой, тем самым способствуя развитию рынка вспомогательных услуг в целях повышения конкурентоспособности каждого предприятия.

Необходимость совершенствования предпринимательской экосистемы для содействия движению предпринимательства и развитию бизнеса:

- Содействие активной связи университетов, научно-исследовательских центров с предприятиями в применении и коммерциализации результатов научных исследований, особенно в области информационных технологий, сельском хозяйстве, которые применяют высокие технологии. Продолжать развивать связующую роль Министерства науки и техники, а также содействовать развитию центров, где реализуется спрос-предложения технологий, посредством организации семинаров, форумов, ярмарок, касающихся технологий.

- Продолжать совершенствовать инфра- 
структуру обслуживания бизнеса, особенно транспортную систему, канализации, промышленные зоны. Проявлять интерес к формированию промышленного кластера, где действуют крупный бизнес, транснациональные корпорации для привлечения бизнеса в вспомогательные отрасли. С другой стороны, Вьетнам также нуждается в создании и внедрении подходящих механизмов и политики для побуждения частных компаний к инвестированию в инфраструктуру и транспорт.

- Создать орган-посредник, в котором будут все программы Правительства по поддержке бизнеса, чтобы для предприятий и предпринимателей информация о них была легко доступна.

\section{Библиографический список}

1. Глобальный мониторинг предпринимательства. URL: https://www.gemconsortium.org/report

2. Постановление Премьер-министра № 844 / QD-TTg от 18 мая 2016 года об утверждении проекта «Поддержка экосистемы стартапов для запуска инноваций до 2025 года» с целью набора организаций, предоставляющих вспомогательные услуги».

3. Chaston, I., \& Scott, G. J. (2012). Entrepreneurship and open innovation in anemerging economy. Management Decision, 50(7), 1161-1177. http://dx.doi.org/10.1108/00251741211246941 